Поэтика символических жестов в романе «Идиот»

Аннотация: В статье рассматриваются специфика и функции драматических эффектов, символических театрализованных жестов аффектации, отражающих эмоциональное напряжение и особенности коммуникации героев, а также их роль и место в развитии романа «Идиот». Обосновывается связь романной формы и драматической: влияние юношеских театральных увлечений автора и западноевропейского романтизма, главным образом немецкого и французского. Раскрывается система жестов в поздних романах, классификация, необходимая для представления аффектации в «Идиоте». Разбор наиболее значительных театральных жестов приводит к заключению об уникальности романа.

Ключевые слова: романы Ф.М. Достоевского, жест, символ, роман-драма, аффектация, патетика, реальные жесты, воображаемые жесты, поступок

A.N. Subbotina (Moscow, Russia)

\title{
Poetics of Symbolic Gestures in the Novel "Idiot"
}

Abstract: The article deals with the specificities and functions of dramatic effects, symbolic theatrical gestures of affectation, reflecting the emotional tension and communication features of the characters, as well as their role and place in the course of the novel "The Idiot". The bond between the novel form and the dramatic one is explained: the influence of the author's interest in drama and theatre in his youth and of Western European romanticism, mainly German and French. The system of gestures in later novels is inferred - the classification, necessary to represent affectation in "The Idiot". The analysis of the most significant theatrical gestures leads to the conclusion that the novel is most ingenious.

Key words: Dostoevsky's novels, gesture, symbol, novel-drama, affectation, pathetic, real gestures, imaginary gestures, act

Общеизвестно, что герои Достоевского характеризуются страстностью, неуравновешенностью, внешне проявляющимися в почти болезненной аффектации. Отсюда и берет начало особая поэтика жестов персонажей, необходимая для их психологического портрета. Речь идет не только о чрезмерной жестикуляции часто встречающейся, но свойственной далеко не всем персонажам, но и об осо- 
бом наборе демонстративных жестов, символически обозначающих отношение к оппоненту, таких как поклоны, поцелуи, или, наоборот, удары, пощечины, плевки и т.д. Особенность жестов такого рода в том, что они, благодаря заключенному в них конвенциональному культурному коду, одновременно становятся постуnками, приводящими к качественному сдвигу в отношениях между персонажами, и, таким образом, в отличие от обыкновенной жестикуляции, они оказываются сюжетно значимыми. Из-за частого использования их в драматических жанрах они воспринимаются как сценические или театрализованные, однако их бытование гораздо шире: они были значимы в средневековой и во всех церемониальных культурах, а в новое время символизация чувства в жесте сделалась актуальной в литературе эпохи романтизма. Ну и, разумеется, говорящие жесты аффектации извечно были в большом ходу в массовой литературе и народном творчестве, эксплуатирующих сильные и броские психологические эффекты. Тем неожиданней наблюдать маркированное использование их Достоевским, что совершенно нетипично для русского реалистического романа. Это и является темой настоящей статьи.

Жесты аффектации - неотъемлемая часть характеристики романного героя Достоевского. Специфика любого жеста такова, что если вербальные отношения, как правило, могут длиться долго, то жесты - это разовое действие. Преувеличенная жестикуляция всегда рассчитана на публичный, массовый эффект, это своего рода гипербола «обычного» человеческого поведения, что соответствует специфической поэтике Достоевского: «Достоевский любил “театральность”, “эффектность”, неожиданные повороты действия и запоминающиеся концовки актов» [Альтшуллер 1983: 59].

Отношения между персонажами в романах Достоевского всегда строятся конфликтно и алогично; кроме того, они не показываются в развитии и изображены дискретно - в одной или двух их встречах, зачастую прилюдных и, как правило, заканчивающихся расставанием, ссорой или разрывом. Вследствие этого художественная роль жестов персонажей на протяжении этих сцен крайне интенсифицируется: на них лежит задача максимально и моментально раскрыть эмоциональный потенциал всех участников сцены и осуществить новый поворот действия. Поэтому на протяжении всего романа именно символические говорящие жесты помогают достичь той степени накала страстей, при которой практически каждая сцена становится кульминационной. Яркая манифестационность, вплоть до эпатажности, подобных жестов разрушает нормативность поведения в обществе и протекания дискурса, что как нельзя более соответствует «поэтике скандалов» у Достоевского ${ }^{1}$.

Известно, что Достоевский с юношеских лет увлекался театром. Академик М.П. Алексеев одним из первых поставил вопрос о необходимости изучения особенностей стилистики Достоевского и сюжетных источников в его произведениях в связи с театрально-драматургическими увлечениями его юности, связывал ранние драматические произведения Достоевского с романтизмом. «Может показаться, что свое литературное воспитание Достоевский получил в театре, а мастерству писателя обучался на драматических образцах» [Алексеев 1921: 43]. Но ранние драматургические опыты, попытки написать «своего» «Бориса Годунова», «Марию Стюарт» не сохранились. Однако принципы и элементы драматургических произведений по-своему реализовались в его «романах-драмах».

\footnotetext{
${ }^{1}$ См. об этом: Криниизын А.Б. Сюжетология романов Достоевского. М., 2017. С. 278-305.
} 
С самого раннего детства и до последних лет творчества сохранялось и росло влияние на Достоевского Шиллера. Драматизм и романтическая аффектация у двух авторов очень похожи. Например, в «Марии Стюарт» особого внимания заслуживает сцена встречи двух соперниц с последующей развязкой. В «Идиоте» это Настасья Филипповна и Аглая, а в «Братьях Карамазовых» - Катерина Ивановна и Грушенька. В обоих случаях соперницы по ходу сцены меняются местами: доминировавшая вначале героиня неожиданно оказывается побежденной.

Немаловажной оказалась для Достоевского и французская романтическая традиция, прежде всего Виктор Гюго, как в драмах, так и в прозе: так, в романе «Отверженные» Фантина на протяжении одной сцены сначала расцарапывает лицо обидевшего его господина, затем в участке целует полу пиджака Жавера, затем плюет в лицо мэру (Жану Вальжану), а потом, в порыве раскаяния, опускается перед ним на колени и иелует у него руку. Или Квазимодо сначала пытается задушить Клода Фролло, а затем встает на колени перед ним. Примеры можно множить бесконечно, потому что вся проза Гюго построена на театральных жестах и эффектных сценах такого рода. Насколько сильно проникнулся Достоевский творчеством Гюго, видно уже по тому, что он в 1862 г. называл его «бесспорно сильнейшим талантом, явившимся в девятнадцатом столетии во Франции»; «Идея его пошла в ход; даже форма теперешнего романа французского чуть ли не принадлежит ему одному» (Достоевский 1972-1990, 20: 29). Хотя Достоевский позднее критиковал Гюго за «страшные художественные ошибки», он отмечал, что «то, что у него вышло без ошибок, равняется по высоте Шекспиру» (Достоевский 1972-1990, 24: 119). Таким образом, для Достоевского драматические приемы и эффекты в прозе выглядели вполне допустимыми при соблюдении минимальных условий правдоподобия, поскольку они помогали ему поддерживать максимальное психологическое напряжение на возможно большем протяжении романного времени. Символические аффектные жесты являлись ключевым элементом данной поэтики драматизации, будучи необходимыми в качестве развязок сцен.

В поздних романах Достоевского сложилась целая система подобных жестов, контрастных и по семантике, и по символике. Многочисленны пощечины, удары, плевки, осквернение святыни (плевок на икону или ее разбивание). Оригинальными являются жесты манипуляций с деньгами - их топтание, бросание в огонь, бросание их в лицо дающим ради демонстрации гордости. А также проклятия на «театральный манер», эпатаж. Совершенно особой семантикой обладает поклон. Значимы поцелуи - прямые выражения любви или же поцелуй портрета, письма, шпаги (эпизод с Дмитрием Карамазовым). Несомненно, такого рода действия объясняются личностными качествами героев. Романтичность, мечтательность и, что особенно важно, экзальтированность в высшей степени, неустойчивое настроение, возбудимость приводят к неуравновешенности и вспыльчивости, эмоциональным эксцессам. Чрезмерная аффектация и наклонность героев к патетике лежит и в основе столь характерного для творчества Достоевского явления, как шутовство.

Хотя символические жесты часты во всех романах «пятикнижия», неповторимость романа «Идиот» состоит в том, что практически каждый подобный жест в нем уникален (в большем числе, чем в других романах). При этом жесты разнообразны по виду и степени реализованности: так, допустима классификация их на реальные ${ }^{1}$ и воображаемые жесты.

\footnotetext{
1 Здесь и далее при цитировании выделения жирным шрифтом принадлежат автору статьи. - A.C.
} 
Реальные (совершённые) жесты: те, которые имели место в жизни героев, могли повлиять на их дальнейшую судьбу. Скажем, обмен крестами Рогожина и Мышкина:

- Поменяться крестами хочешь? Изволь, Парфен, коли так, я рад; побратаемся!

Князь снял свой оловянный крест, Парфен свой золотой, и поменялись. <..> - Матушка, - сказал Рогожин, поцеловав у нее руку, - вот мой большой друг, князь Лев Николаевич Мышкин; мы с ним крестами поменялись; <...> Благослови его, матушка, как бы ты родного сына благословила [Достоевский 1972-1990, 8: 185].

С точки зрения сюжета это значимый жест, поскольку впоследствии произойдет роковое событие - Рогожин занесет нож над «братом». По сути, ситуация обмена крестами - обмен судьбами и вместе с тем единение с народом: Рогожин берет на себя крест солдата, у которого купил крест Мышкин.

Воображаемые (несостоявшиеся, потенциальные) жесты: семантика подобных жестов любопытна в еще большей степени. Аглая сначала рассказывает князю, что Ганя в доказательство своей любви сжег перед ней палец на свечке, но потом все-таки признается, что этого не было:

Знайте, что он исправился; он любит меня более своей жизни. Он предо мной сжег свою руку, чтобы только доказать, что любит меня более своей жизни. <..> Зажег свечку и целые полчаса держал палец на свечке; разве это не может быть? [Достоевский 1972-1990, 8: 360];

генерала Иволгина постоянно уличают во лжи, например, Настасья Филипповна после рассказа о выброшенной из вагона болонке говорит, что уже читала подобный пассаж в газете «Indépendance»:

Не говоря ни слова, я с необыкновенною вежливостью, с совершеннейшею вежливостью, с утонченнейшею, так сказать, вежливостью, двумя пальцами приближаюсь к болонке, беру деликатно за шиворот и шварк ее за окошко вслед за сигаркой! Только взвизгнула! Вагон продолжает лететь... [Достоевский 1972-1990, 8: 93].

Жест можно отнести к эпатажным жестам (выходящим за рамки всех приличий). Генерал думал сей удивительной повестью рассмешить и, так сказать, возвыситься в глазах великолепной гостьи Настасьи Филипповны. Но произошло совершенно наоборот. Неудавшийся рассказ только подчеркивает уже начинавшуюся «болезнь», любовь генерала к неправдоподобным и намеренно жеманным и натянутым повествованиям, впоследствии героя будут считать даже за лжеца и плута. Примечательно, что генерал не различает, что из сказанного истинно, а что нет, в итоге один-единственный раз угадывает правильно, - обычно подобные фразы необходимы ему для начала разговора, - он действительно носил на руках Аглаю:

$<. .>$ что он ногу эту поднял и отнес домой, потом похоронил ее на Ваганьковском кладбище и говорит, что поставил над нею памятник с надписью с одной стороны: “Здесь погребена нога коллежского секретаря Лебедева", а с другой: “Покойся, милый прах, до радостного утра", и что, наконец, служит ежегодно по ней панихиду (что уже святотатство) и для этого ежегодно ездит в Москву [Достоевский 1972-1990, 8: 411];

Вы, кажется, смотрите на меня с удивлением? Генерал Иволгин, имею честь рекомендоваться. Я вас на руках носил, Аглая Ивановна [Достоевский 1972-1990, 8: 203].

Наибольший интерес представляют несостоявшиеся потенциальные жесты. Ну, простите, ну, простите же! - нетерпеливо настаивал Ганя, - ну, хотите, я вашу руку сейчас поцелую! [Достоевский 1972-1990, 8: 101]. 
Примечательно, что целуют руку в романе в основном у князя Мышкина.

Между реальными и воображаемыми жестами нет разницы, по существу, действительность переходит в анекдот - и наоборот. Возникает ощущение карнавальной атмосферы, ирреальности происходящего.

В «Идиоте» наряду с культурно-конвенциональными символическими жестами, такими как поцелуи, коленопреклонение, пощечина и др., существуют и исключительные, неповторимые, которых в других произведениях нет. Например, эпизод с разбиванием вазы, который занимателен тем, что накануне Мышкин с Аглаей предсказывали эту «катастрофу». Столь же оригинален и непредсказуем финальный эпизод первой части - сожжение ста тысяч Настасьей Филипповной. Символична вся сцена: разрушается овеществление любви и свободы. Знаменательно, что в каждом романе «пятикнижия» присутствует подобный акт демонстративного пренебрежения деньгами. Вкупе можно говорить о некой системе символов, складывающейся на основе мировоззрения героев и их отношения к материальным благам. В целом для героев Достоевского характерно презрительное отношение к деньгам: Снегирев топчет деньги, а Ставрогин бросает их в грязь, Катерина Ивановна и Аркадий Долгорукий швыряют их в своих обидчиков. Также символической оказывается первая встреча в квартире Гани Мышкина и Настасьи Филипповны, которая принимает того за лакея:

- Князь? Он князь? Вообразите, а я давеча, в прихожей, приняла его за лакея <..> [Достоевский 1972-1990, 8: 89].

Такие жесты, как удары, пощечины, плевки и др., предстают как признак безобразия мира, когда расшатывается нормальное общение и жестокость, превосходство одного над другим превалируют.

Несколько мгновений они простояли так друг против друга, лицом к лицу. Ганя все еще держал ее руку в своей руке. Варя дернула раз, другой, изо всей силы, но не выдержала и вдруг, вне себя, плюнула брату в лицо [Достоевский 1972-1990, 8: 99].

Трагизм положения в том, что родные брат и сестра считают себя врагами, а плевок - выражение наивысшей степени презрения, нанесение кровной обиды, стремление унизить еще больше, тем более публично, при невесте.

Удары, по распространению соперничающие с коленопреклонением, по интенсивности и контрастной семантике занимают значительное место в системе жестов. Их насыщенность позволяет говорить о том, что катастрофичность сознания и безобразие окружающего характеризуют мир героев Достоевского.

Тут просто хлыст надо, иначе ничем не возьмешь с этою тварью! - почти громко проговорил он [Достоевский 1972-1990, 8: 290].

Настасья Филипповна защищала свою честь, жестоко отомстив своему обидчику:

Настасья Филипповна мигом обернулась к нему. Глаза ее сверкнули; она бросилась к стоявшему в двух шагах от нее и совсем незнакомому ей молодому человеку, державшему в руке тоненькую плетеную тросточку, вырвала ее у него из рук и изо всей силы хлестнула своего обидчика наискось по лицу [Достоевский 1972-1990, 8: 290-291].

Эффектный удар тросточкой по лицу как один из ярчайших примеров сценического жеста позволяет проследить одну из сторон многогранного характера героини - жестокость и бескомпромиссность.

Обратная ситуация связана с эмоциональной сферой отношений, когда жесты представляют собой проявление детскости и открытости - как в случае князя 
Мышкина. Но детскость, являющаяся необходимой для достижения гармонии, в финале романа ставится под сомнение жестом, символизирующим ее беспомощность: герой в бреду гладит по голове Рогожина, как ребенка:

Князь сидел подле него неподвижно на подстилке и тихо, каждый раз при взрывах крика или бреда больного, спешил провесть дрожащею рукой по его волосам и щекам, как бы лаская и унимая его [Достоевский 1972-1990, 8: 507].

Такой жест, как целование рук, живописует духовное перерождение, благодарность и любовь. Этот жест, выполняющий в культуре того времени функцию приветствия или прощания, в романном творчестве Достоевского расширяет семантику за счет дополнительных смыслов. В отличие от остальных жестов, целование рук практически всегда положительный символ: наивысшее проявление любви, уважения, преданности, благодарности либо мольба, извинение. При этом целование рук не является унижением, человек, способный к возрождению, - живой («холоден или горяч, но не тепел»). Проявлений чистой любви крайне мало (возможны поцелуи, коленопреклонение), как правило, страсть, любовь-ненависть - дионисийское начало - превалируют над иными чувствами. Следовательно, следующие жесты исключительны в своем роде.

Целование рук как бы встраивается в евангельский контекст в романе «Идиот». Две грешницы - Мари и Настасья Филипповна - целуют руку у князя Мышкина, «святого»: возможная отсылка к Марии Магдалине и Иисусу Христу.

Как я только показывался, Мари тотчас же вздрагивала, открывала глаза и бросалась целовать мне руки [Достоевский 1972-1990, 8: 62].

Мари считала, и вполне обоснованно, Льва Николаевича за своего спасителя и благодетеля, который помог детям, кидавшим в нее грязью, понять истинную суть вещей и полюбить несчастную. Целование рук тем самым символизирует собой идею искупления грехов. Интересно, что впоследствии, когда Настасья Филипповна припадет к ногам князя, ища его руку, чтобы поцеловать, возникнет тот же контекст и ассоциация:

Она опустилась пред ним на колена, тут же на улице, как исступленная; он отступил в испуге, а она ловила его руку, чтобы целовать ее, и точно так же, как и давеча в его сне, слезы блистали теперь на ее длинных ресницах [Достоевский 1972-1990, 8: 381-382].

Так или иначе, но практически все поклонники Настасьи Филипповны: генерал Епанчин, Ганя Иволгин, Парфен Рогожин - пытались ее «купить». По сути, только Мышкин увидел в ней ее страдающую, ранимую душу. Неслучайно она после первого знакомства с семьей своего будущего мужа Гани говорит его матери Нине Александровне о Мышкине:

- Я ведь и в самом деле не такая, он угадал <..>» [Достоевский 1972-1990, 8: 100].

А до этого жест, поразивший присутствовавших:

Но, не дойдя еще до прихожей, вдруг воротилась, быстро подошла к Нине Александровне, взяла ее руку и поднесла ее к губам своим [Достоевский 1972-1990, 8: 100].

Героиня осознает всю низость помыслов Гани и собственного поступка, но, увлекаемая Рогожиным в бездну, к Нине Александровне она испытывает неподдельное чувство уважения и почтения.

Жест коленопреклонения является самым распространенным и самым многозначным. Его модификации приводят к тому, что семантика жеста может транс- 
формироваться до резко отрицательного значения. Первичный смысл его - «смириться, поклониться, повиноваться, попросить». Коленопреклоненная Настасья Филипповна пытается поцеловать руку князю Мышкину, тем самым обнажается ее истинная сущность:

Она опустилась пред ним на колена, тут же на улице, как исступленная; он отступил в испуге, а она ловила его руку, чтобы целовать ее, и точно так же, как и давеча в его сне, слезы блистали теперь на ее длинных ресницах [Достоевский 1972-1990, 8: 381-382].

В таком контексте подобный жест символизирует благодарность и уважение, преклонение и преданность.

Однако «вставание на колени» может видоизмениться в жест унижения - когда герои заставляют встать на колени других в знак своей власти над ними, как правило, в присутствии наибольшего количества героев. Например, когда Настасья Филипповна вспоминает о готовности Гани проделать это:

- Ганька, ко мне мысль пришла: я тебя вознаградить хочу, потому за что же тебе все-то терять? Рогожин, доползет он на Васильевский за три целковых?

- Доползет! - <...> Как только огонь обхватит ее всю, - полезай в камин, но только без перчаток, с голыми руками, и рукава отверни, и тащи пачку из огня! Вытащишь - твоя, все сто тысяч твои! <..> А я на душу твою полюбуюсь, как ты за моими деньгами в огонь полезешь [Достоевский 1972-1990, 8: 144].

Оскорбление станет невыносимым для самолюбия героя. Это высший предел унижения для человека. Даже для такого, на первый взгляд, расчетливого и мелочного Гани подобный призыв равносилен самоубийству. Тем более Настасья Филипповна открыто стремится отомстить своему несостоявшемуся жениху за то, что тот на ней из-за большого приданого жениться хотел.

Склонен к подобным манифестациям и злобный шут Фердыщенко, который унижает всех часто и прилюдно. Например, как рассматривать его предложение сыграть в разоблачительное пёти-же с участием уважаемых и почтенных лиц Тоцкого и генерала Епанчина?

Благодаря незаслуженным оскорблениям и демонстративному пренебрежению, парадоксальным образом иногда становятся возможны «вечные» минуты примирения и воссоединения. Аглая после разбитой китайской вазы совершенно иначе смотрит на Мышкина. Когда кто-либо преодолевает стыд показаться смешным в глазах общества, складывается новый уровень отношений, всеобщая предельная близость, в конечном итоге являющаяся моделью «райской гармонии» между людьми.

Следующий жест характерен для героев романтически эмоциональных, например генерала Иволгина.

Старик побагровел, поднял руки и прокричал:

- Довольно! Проклятие мое... прочь из этого дома! [Достоевский 1972-1990, 8: 396].

Или:

Генерал остановился, обернулся, простер свою руку и воскликнул:

- Проклятие мое дому сему!

- И непременно на театральный тон! - пробормотал Ганя, со стуком запирая окно [Достоевский 1972-1990, 8: 400].

Преднамеренная аффектация - отличительная черта шута в мире Достоевского. Генерал Иволгин бессознательно играет роль «человека в низости»; происходит 
конфликт с окружающими, которые не могут всерьез воспринимать его поведение и речь. Верно заметил Ганя: «непременно на театральный тон!» Генерал, один из самых «театральных» героев в романе, произносит те или иные восклицания с нарочитой изощренностью, наигранностью, с целью усилить эффект от сказанного перед зрителями. Патетика и трагика жестов, знаменующих безобразие мира и низшую природу человека, переходят в комизм и гротеск. В целом, комическая семантика у жестов актуализируется часто. Генерал Иволгин - все-таки это фигура трагичная - бессознательно выступает в роли шута, поэтому проклятие родному дому, наивысшая степень раскола и катастрофичности, оборачивается комедией вследствие нарочитой наигранности в поведении и речи героя.

Отметим, что показаться смешным, неловким боятся все герои романа, кроме шутов.

Демонстративными жестами могут сопровождаться и решающие действия героев, не только имеющие символическое значение, но кардинально воздействующие на судьбу самого героя и его окружающих. Например, попытка публичного самоубийства Ипполита как вызов Богу и обществу (символично его желание убить себя при закате солнца, перед этим простившись с Человеком, т. е. с князем), кидание камней в Мари детьми, что им представляется игрой, но в контексте евангельских мотивов романа порождает символическую ассоциацию с блудницей, спасенной Христом от избиения камнями.

...дети, всею ватагой, < ..> стали дразнить ее и даже грязью в нее кидали;

Они начали свистать, хлопать в ладошки и смеяться, а Мари бросилась бежать. Я хотел было говорить, но они в меня стали камнями кидать» [Достоевский 1972-1990, 8: 59-60]).

Данный эпизод вполне мог привести к гибели Мари, подобно тому как Илюша Снегирев в «Братьях Карамазовых» погибает от надорвавшего ему грудь камня, повлекшего развитие смертельной болезни. Однако после, впечатленные речами Мышкина, дети меняют свое отношение к несчастной, что выражается, в частности, и в тысячах поцелуев, которыми они хотят ее утешить.

Итак, мы разобрали на примерах, какую функцию в романах Достоевского выполняют драматические эффекты и символические театрализованные жесты аффектации, отражающие эмоциональное напряжение и специфику коммуникации героев. Драматизация образов, огромное влияние романтиков, чем непосредственно обусловлены частотность и качество символических жестов. Коленопреклонения и поцелуи руки, пощечины и др. образуют цельную поэтическую систему в романах «пятикнижия». Частая жестикуляция говорит о том, что герои отказываются от длительного действия в пользу моментального, способного лучше выразить умонастроения в конкретную минуту. Уникальные жесты, например сжигание денег, разбитие вазы, создают исключительность художественного рисунка романа «Идиот». Ощущение карнавальной атмосферы в романе достигается также за счет неразличимости реальных и воображаемых жестов.

\section{ЛИТ РАТ У РА}

Альтшуллер А. Достоевский и русский театр его времени // Достоевский и театр: Сборник статей / Под ред. А.А. Ниновой. Л.: Искусство, 1983. С. 59-83.

Алексеев М.П. О драматических опытах Достоевского // Творчество Ф.М. Достоевского. 1821-1881-1921: Сборник статей и материалов / Под ред. Л.П. Гроссмана, Одесса: Всеукраинское государственное издательство, 1921. С. 43-98. 
Достоевский Ф.М. Полн. собр. соч.: В 30 т. / Редкол.: В.Г. Базанов (отв. ред.) и др.; ИРЛИ. Т. 8. Л.: Наука, Ленинградское отделение, 1973. 511 с.

Достоевский Ф.М. Полн. собр. соч.: В 30 т. / Редкол.: В.Г. Базанов (отв. ред.) и др.; ИРЛИ. Т. 20. Л.: Наука, Ленинградское отделение, 1980. 432 с.

Достоевский Ф.М. Полн. собр. соч.: В 30 т. / Редкол.: В.Г. Базанов (отв. ред.) и др.; ИРЛИ. Т. 24. Л.: Наука, Ленинградское отделение, 1982. 518 с.

\section{REF E R E N CES}

Altshuller A. Dostoevsky and the Russian Theater of His Time. In: Dostoevsky and Theater: Digest of Articles / Ed. by A.A. Ninova. Leningrad. Iskusstvo Publ. 1983, pp. 59-83.

Alekseev M.P. On the Dramatic Experiments of Dostoevsky. In: Creativity of F.M. Dostoevsky. 1821-1881-1921. Collection of articles and materials / Ed. by L.P. Grossman. Odessa. Vseukrainskoje gosudarstvennoje izdatelstvo Publ. 1921, pp. 43-98.

Dostoevsky F.M. Complete Works: In 30 vols. / Ed.: V.G. Bazanov (editor-in-chief) et al.; IRLI. Vol. 8. Leningrad. Nauka Publ. 1973. 511 p.

Dostoevsky F.M. Complete Works: In 30 vols. / Ed.: V.G. Bazanov (editor-in-chief) et al.; IRLI. Vol. 20. Leningrad. Nauka Publ. 1980. 432 p.

Dostoevsky F.M. Complete Works: In 30 vols. / Ed.: V.G. Bazanov (editor-in-chief) et al.; IRLI. Vol. 8. Leningrad. Nauka Publ. 82. 518 p.

Сведения об авторе:

Анна Николаевна Субботина,

студент

филологический факультет

МГУ имени М.В. Ломоносова
Anna N. Subbotina,

Student

Philological Faculty

Lomonosov Moscow State University

a.n.subbotina@mail.ru 